\section{Fungicide Seed Treatment Effects on Seed-borne Ascochyta rabiei in Chickpea}

\author{
Kiersten A. Wise ${ }^{1,4}$, Robert A. Henson ${ }^{2,5}$, and Carl A. Bradley ${ }^{3,6}$
}

AdDitionAl INDEX words. Allegiance, Dynasty, garbanzo bean, legume, LSP, Vortex

SUMMARY. A chickpea (Cicer arietinum) seedlot, naturally infected with Ascochyta rabie $i$, was sorted into two lots of asymptomatic and symptomatic, based on visual symptoms observed. A laboratory assay showed $16 \% A$. rabiei infection in asymptomatic seeds, while symptomatic seeds had $73 \%$ infection. Asymptomatic and symptomatic seeds were treated with different fungicides to determine their effects on seedling emergence from soil and on ascochyta blight development in seedlings grown in a growth chamber and in the field at Fargo and Carrington, ND, in 2006. The emergence of seedlings grown from asymptomatic seeds was significantly $(P \leq \mathbf{0 . 0 5})$ greater than the emergence of seedlings grown from symptomatic seeds in the growth chamber and field trials. Fungicides were able to increase plant emergence from symptomatic seeds when compared with a control in the growth chamber trials. In the growth chamber trials, the treatment with a mixture of metalaxyl + thiabendazole + ipconazole + azoxystrobin was the most effective at slowing the development of disease on plants from symptomatic seeds. This research reinforces the importance of seed health testing and fungicide seed treatments as part of an ascochyta blight management program.

A scochyta blight, caused by Ascochyta rabiei (teleomorph Didymella rabiei), is the most destructive foliar fungal disease of chickpea in the world (Gan et al., 2006; Nene and Reddy, 1987). Although chickpea cultivars with moderate levels of resistance to $A$. rabiei have been developed, resistance has not been durable due to the development or selection of pathotypes of the fungus that overcome host resistance (Chen et al., 2004; Chongo et al., 2004). An integrated approach that combines different management practices is the best way to manage ascochyta blight of

We thank the Northern Pulse Growers Association (formerly the North Dakota Dry Pea and Lentil Association) and the United States Department of Agriculture - Cooperative State Research, Education, and Extension Service (USDA-CSREES) Cool Season Food Legume Research Program for providing financial support for a graduate research assistantship.

We thank C. Chesrown, B. Schatz and the staff at the Carrington Research Extension Center for assisting with the field trials, and $\mathrm{B}$. Tarang for assisting with the growth chamber trials.

${ }^{1}$ Department of Plant Pathology, North Dakota State University, Fargo, ND 58108

${ }^{2}$ Carrington Research Extension Center, North Dakota State University, Carrington, ND 58421

${ }^{3}$ Department of Crop Sciences, University of Illinois, Urbana, IL 61801

${ }^{4}$ Present address: Department of Botany and Plant Pathology, Purdue University, West Lafayette, IN, 47907.

${ }^{5}$ Deceased.

${ }^{6}$ Corresponding author. E-mail: carlbrad@illinois.edu. chickpea (Gan et al., 2006). Integrated management programs include crop rotation, seed certification and testing, fungicide seed treatment, partially resistant cultivars, and foliar fungicide applications (Akem et al., 2004a, 2004b; Chongo et al., 2003; Chongo and Gossen, 2003; Gan et al., 2006; Shtienberg et al., 2000).

Recently, populations of $A$. rabiei resistant to the quinone outside inhibitor (QoI) fungicides azoxystrobin and pyraclostrobin were identified in North Dakota (Wise et al., 2009). Long-range dispersal of $A$. rabiei can occur through infected chickpea seed (Kaiser, 1997). It has been hypothesized that $A$. rabiei was likely first introduced into North America with seed imported to Canada in 1973 (Morrall and McKenzie, 1974). Movement of infected seed could be a possible mode of distribution of QoI fungicide-resistant $A$. rabiei populations throughout North America and beyond. Chickpea seeds infected with $A$. rabiei can germinate, but generally at a reduced rate (Kaiser and Hannan, 1988; Kaiser et al., 1973). A. rabiei can spread from infected seeds to emerging seedlings at a high rate (Demirci et al., 2003; Kaiser and Hannan, 1988; Kaiser et al., 1973; Maden et al., 1975). In turn, these infected seedlings serve as foci for new infections in a field (Gan et al., 2006). Because of the important role that infected seed can play in the epidemiology of ascochyta blight in a field, all certified chickpea sold in North Dakota must be tested for A. rabiei infection, and seed lots with greater than $0.3 \%$ infection rate are not recommended for planting (Markell et al., 2008). The objective of this research was to evaluate the effects of fungicide seed treatments on controlling seed-borne $A$. rabiei in chickpea.

\section{Materials and methods}

Fungicide SEED TREATMENTS. A chickpea seedlot (cultivar Dwelley) was obtained from a producer's field in North Dakota that was affected by ascochyta blight and harvested in 2004 . The seeds were individually sorted by hand into two categories, asymptomatic and symptomatic seeds, based on visual observations. The asymptomatic seed category included seed that were uniform in size and color and appeared healthy, without any discoloration, shriveling, or lesions. The symptomatic seed category included those that had visible lesions.

Chickpea seeds from each category were evaluated in the laboratory using an agar plate method to determine germination and $A$. rabiei infection levels. The agar plate method is a recommended seed health testing method for chickpea (Mathur and Kongsdal, 2003). Seeds were surface disinfested by soaking in a $0.5 \%$ sodium hypochlorite $(\mathrm{NaOCl})$ solution for $5 \mathrm{~min}$ with constant agitation, 
followed by a rinse in sterile distilled water for 5 min with agitation. Seeds were then dried overnight in a laminar flow hood. After the seeds were dried, they were placed onto potato dextrose agar [PDA (Difco Laboratories, Detroit, MI)] in petri dishes $(100 \times$ $15 \mathrm{~mm}$ ), with five seeds per plate, for a total of 20 plates per seed category. Seeds were incubated at $20 \pm 2{ }^{\circ} \mathrm{C}$ in the dark for $4 \mathrm{~d}$, followed by $3 \mathrm{~d}$ under a diurnal light cycle ( $12 \mathrm{~h}$ light/ $12 \mathrm{~h}$ dark) at the same temperature. Each seed was scored for germination and A. rabiei infection. A seed was considered germinated if the radicle was as long as the diameter of the seed. Seeds infected with $A$. rabiei were confirmed by examining conidia of symptomatic samples at $100 \times$ magnification under a microscope. The experimental design was a completely randomized design with individual plates serving as replicates (20 replicates total per seed category), and the experiment was repeated once. Data were analyzed using the general linear model procedure (PROC GLM) in SAS (SAS Institute, Cary, NC).

Seeds within each category were left untreated or treated with one of the following treatments: metalaxyl (Allegiance FL; Bayer CropScience, Research Triangle Park, NC) at $16 \mathrm{~g} / 100 \mathrm{~kg}$ seed; thiabendazole (LSP Flowable Fungicide; Bayer CropScience) at $72 \mathrm{~g} / 100 \mathrm{~kg}$ seed + metalaxyl; ipconazole (Vortex; Bayer CropScience) at $3 \mathrm{~g} / 100 \mathrm{~kg}$ seed + metalaxyl; azoxystrobin (Dynasty; Syngenta Crop Protection, Greensboro, NC) at $5 \mathrm{~g} / 100 \mathrm{~kg}$ seed + metalaxyl; or a combination of thiabendazole + ipconazole + azoxystrobin + metalaxyl. Chickpea seeds were treated with slurries of the fungicides in a zipper-seal type plastic bag and shaken vigorously for $\approx 2 \mathrm{~min}$ to ensure a uniform coating. Metalaxyl fungicide is not known to have any efficacy on Ascochyta, and was used to protect against Pythium infection in the field (Hewitt, 1998). In North Dakota, chickpea seeds not treated with metalaxyl or its active isomer, mefenoxam, are prone to emergence problems due to Pythium (C.A. Bradley, personal observation). All other fungicides used in these research trials are registered for control of $A$. rabiei on chickpea seeds in the United States or have been shown to control $A$. rabiei in experimental research trials (K.M. McKay, personal communication).

Field TRIALs. Field trials were established at the North Dakota State University Agricultural Experiment Station in Fargo and the North Dakota State University, Carrington Research Extension Center in Carrington in 2006. Both fields had been planted with soybean (Glycine max) in 2005. The Fargo field had no history of chickpea production, while the Carrington field had a history of chickpea production, with the last year of chickpea production being in 2002. Both locations were planted using single-row plots (15-inch row spacing and 30 seeds per plot). Due to differences in equipment, plot lengths differed at each location where plots were $15 \mathrm{ft}$ long at Fargo and $10 \mathrm{ft}$ long at Carrington. About 5 weeks after planting, the number of emerged plants for each plot was determined, and percentage of emergence was calculated based on 30 seeds planted per plot. The experimental design at both locations was a randomized complete block (RCB) with four replications at the Fargo location and three replications at the Carrington location. Data were analyzed using PROC GLM in SAS, and means were compared using Fisher's protected least significant difference (LSD) test $(\alpha=0.05)$. A single-df contrast statement was used to compare emergence of plants that developed from asymptomatic seeds versus symptomatic seeds.

Growth Chamber trials. Chickpea seeds were planted in 16-fl oz plastic drinking cups (five seeds per cup) filled with a potting mix (Sunshine Mix Number 1; Sun Gro Horticulture, Bellevue, WA) and were placed into a growth chamber (Controlled Environments, Winnipeg, $\mathrm{MB}$, Canada). The growth chamber was set at $20{ }^{\circ} \mathrm{C}$ with a diurnal light cycle ( 12 h light $/ 12$ h dark) at $\approx 350$ $\mu \mathrm{mol} \cdot \mathrm{m}^{-2} \cdot \mathrm{s}^{-1}$. Drainage holes were cut into the bottom of the plastic drinking cups before planting, and cups were bottom-watered as needed throughout the experiment. Each cup contained seeds of a single treatment (seed category $\times$ seed treatment). Clear plastic cups (16 fl oz) were inverted and placed over seedlings at first emergence, forming a minidome. This technique, adapted from Chen et al. (2005), ensured that a uniform and high level of relative humidity was present, which favored disease development. Plants were evaluated daily for $21 \mathrm{~d}$ for the development of ascochyta blight lesions, and the number of days after planting (DAP) that a lesion was first observed was recorded; plants that did not develop lesions were recorded as 22 DAP. After $21 \mathrm{~d}$, the number of emerged seedlings was determined. The experimental design was a RCB with three replications, where two cups (10 total seeds) per treatment were considered one experimental unit. The experiment was repeated once. Data were analyzed using PROC GLM in SAS, and means were compared using Fisher's protected LSD test $(\alpha=0.05)$. A single- $d f$ contrast statement was used to compare emergence of plants and the development of ascochyta blight lesions on plants that developed from asymptomatic seeds versus symptomatic seeds.

\section{Results}

Results of the laboratory seed assay indicated that asymptomatic seeds had a significantly $(P=$ 0.0001 ) lower incidence of $A$. rabiei infection (16\%) compared with symptomatic seeds $(73 \%)$. Germination of asymptomatic seeds $(43 \%)$ was significantly $(P=0.0001)$ greater than symptomatic seeds $(23 \%)$.

In the field studies, a significant $(P=0.0001)$ interaction between location and treatment was observed; therefore, results from each location are presented separately. At Fargo, emergence from chickpea seeds that were not treated with a fungicide seed treatment was significantly $(P \leq 0.05)$ lower than from seeds that were treated with a fungicide (Table 1 ). The single-df contrast of "asymptomatic versus symptomatic seeds" indicated that asymptomatic seeds resulted in significantly $(P=0.0082)$ greater emergence than symptomatic seeds ( $74 \%$ vs. $57 \%$, respectively) when averaged over all treatments. Within each seed category, all fungicide seed treatments improved emergence over the untreated control, but no significant differences occurred among the fungicide treatments for emergence.

At Carrington, no significant $(P$ $\leq 0.05$ ) differences among treatments occurred for seedling emergence (Table 2). The single-df contrast of "asymptomatic seeds versus 
Table 1. Fungicide seed treatment effects on the seedling emergence of chickpea plants with Ascochyta rabiei infection at Fargo, ND, in 2006.

\begin{tabular}{llc}
\hline Seed symptoms $^{\mathrm{z}}$ & \multicolumn{1}{c}{ Fungicide $^{\mathrm{y}}$} & Emergence (\%) $^{\circ}$ \\
\hline Asymptomatic & Untreated control & $15 \mathrm{~d}^{\mathrm{x}}$ \\
& Metalaxyl & $75 \mathrm{abc}$ \\
& Thiabendazole + metalaxyl & $82 \mathrm{abc}$ \\
& Ipconazole + metalaxyl & $85 \mathrm{ab}$ \\
& Azoxystrobin + metalaxyl & $98 \mathrm{a}$ \\
& Thiabendazole + ipconazole & $90 \mathrm{a}$ \\
Symptomatic & + azoxystrobin + metalaxyl & $18 \mathrm{~d}$ \\
& Untreated control & $58 \mathrm{bc}$ \\
& Metalaxyl & $56 \mathrm{c}$ \\
& Thiabendazole + metalaxyl & $77 \mathrm{abc}$ \\
& Ipconazole + metalaxyl & $56 \mathrm{c}$ \\
& Azoxystrobin + metalaxyl & $77 \mathrm{abc}$ \\
& Thiabendazole + ipconazole & \\
\hline
\end{tabular}

${ }^{2}$ Asymptomatic seeds appeared healthy and uniform in color and size, but had $16 \%$ A. rabiei infection. Symptomatic seeds contained lesions and had $73 \% A$. rabiei infection.

'Metalaxyl was applied at $16 \mathrm{~g} / 100 \mathrm{~kg}$ seed, thiabendazole was applied at $72 \mathrm{~g} / 100 \mathrm{~kg}$ seed, ipconazole was applied at $3 \mathrm{~g} / 100 \mathrm{~kg}$ seed, and azoxystrobin was applied at $5 \mathrm{~g} / 100 \mathrm{~kg}$ seed $(1 \mathrm{~g} / 100 \mathrm{~kg}$ seed $=0.0160 \mathrm{oz} / 100 \mathrm{lb}$ seed).

'Values followed by the same letter within a column are not significantly different $(\alpha=0.05)$ according to Fisher's protected least significant difference test.

Table 2. Fungicide seed treatment effects on the seedling emergence of chickpea plants with Ascochyta rabiei infection at Carrington, ND, in 2006.

\begin{tabular}{llc}
\hline Seed symptoms $^{\mathrm{z}}$ & \multicolumn{1}{c}{ Fungicide $^{\mathrm{y}}$} & Emergence (\%) $^{\circ}$ \\
\hline Asymptomatic & Untreated control & $39 \mathrm{a}^{\mathrm{x}}$ \\
& Metalaxyl & $50 \mathrm{a}$ \\
& Thiabendazole + metalaxyl & $47 \mathrm{a}$ \\
& Ipconazole + metalaxyl & $56 \mathrm{a}$ \\
& Azoxystrobin + metalaxyl & $39 \mathrm{a}$ \\
& Thiabendazole + ipconazole & $57 \mathrm{a}$ \\
& + azoxystrobin + metalaxyl & \\
Symptomatic & Untreated control & $37 \mathrm{a}$ \\
& Metalaxyl & $37 \mathrm{a}$ \\
& Thiabendazole + metalaxyl & $39 \mathrm{a}$ \\
& Ipconazole + metalaxyl & $40 \mathrm{a}$ \\
& Azoxystrobin + metalaxyl & $34 \mathrm{a}$ \\
& Thiabendazole + ipconazole & $40 \mathrm{a}$ \\
& + azoxystrobin + metalaxyl & \\
\hline
\end{tabular}

${ }^{\mathrm{z}}$ Asymptomatic seeds appeared healthy and uniform in color and size, but had $16 \%$ A. rabiei infection. Symptomatic seeds contained lesions and had $73 \%$ A. rabiei infection.

yetalaxyl was applied at $16 \mathrm{~g} / 100 \mathrm{~kg}$ seed, thiabendazole was applied at $72 \mathrm{~g} / 100 \mathrm{~kg}$ seed, ipconazole was applied at $3 \mathrm{~g} / 100 \mathrm{~kg}$ seed, and azoxystrobin was applied at $5 \mathrm{~g} / 100 \mathrm{~kg}$ seed $(1 \mathrm{~g} / 100 \mathrm{~kg}$ seed $=0.0160 \mathrm{oz} / 100 \mathrm{lb}$ seed).

'Values followed by the same letter within a column are not significantly different $(\alpha=0.05)$ according to Fisher's protected least significant difference test.

symptomatic seeds" indicated that asymptomatic seeds resulted in significantly $(P=0.0033)$ greater emergence than symptomatic seeds $(48 \%$ vs. $38 \%$, respectively).

In the growth chamber trials, the single-df contrast of "asymptomatic seeds versus symptomatic seeds" indicated that asymptomatic seeds resulted in significantly $(P=0.0001)$ greater emergence than symptomatic seeds (94\% vs. $77 \%$, respectively). Within the asymptomatic seed category, no
In the growth chamber trials, the single-df contrast of "asymptomatic seeds versus symptomatic seeds" indicated that lesions developed significantly $(P=0.0001)$ later on plants from asymptomatic seeds compared with plants from symptomatic seeds (20.4 vs. 15.2 DAP, respectively). Among treatments within the asymptomatic seed category, there were no significant differences $(P \leq 0.05)$ in the onset of ascochyta blight lesions (Table 3). Among treatments within the symptomatic seed category, plants that developed from seeds treated with thiabendazole + ipconazole + azoxystrobin + metalaxyl developed lesions later than plants that developed from untreated seeds or seeds treated with azoxystrobin + metalaxyl.

\section{Discussion}

The presence of $A$. rabiei infection on apparently healthy seeds in our research trials reinforces the need for seed health testing as part of an ascochyta blight management program (Chongo and Gossen, 2003; Gan et al., 2006). Similar results have been reported by Dey and Singh (1994) and Maden et al. (1975), in which $6.7 \%$ and $12 \% A$. rabiei infection, respectively, was found on asymptomatic chickpea seed. In this study, asymptomatic seeds also produced seedlings with ascochyta blight symptoms, indicating that even a low level of inoculum on apparently healthy seeds is sufficient to cause disease in a growth chamber environment. In our studies, seed germination and seedling emergence were decreased, and ascochyta blight developed more quickly on plants that developed from symptomatic seeds compared with asymptomatic seeds. Dey and Singh (1994) reported that seedling emergence was decreased and ascochyta blight development on seedlings was increased as seed symptoms increased in severity.

Plant emergence was increased with fungicide seed treatments compared with the untreated control at the Fargo location, but not at the Carrington location. This effect at Fargo was due largely to the metalaxyl seed treatment, which protected against Pythium. The soil at Fargo is a much heavier clay-type soil than that at Carrington, and holds moisture for a long period of time, making a more conducive environment for Pythium 
Table 3. Fungicide seed treatment effects on the seedling emergence and infection of chickpea plants with Ascochyta rabie $i$ infection in a growth chamber study.

\begin{tabular}{|c|c|c|c|}
\hline Seed symptoms ${ }^{\mathrm{z}}$ & Fungicide $^{y}$ & Emergence (\%) & $\begin{array}{c}\text { Lesion } \\
\text { development } \\
(\mathrm{DAP})^{\mathrm{x}} \\
\end{array}$ \\
\hline \multirow{6}{*}{ Asymptomatic } & Untreated control & $95 \mathrm{a}^{\mathrm{w}}$ & $22.0 \mathrm{a}$ \\
\hline & Metalaxyl & $90 \mathrm{abc}$ & $19.7 \mathrm{a}$ \\
\hline & Thiabendazole + metalaxyl & $95 \mathrm{a}$ & $22.0 \mathrm{a}$ \\
\hline & Ipconazole + metalaxyl & $95 \mathrm{a}$ & $20.0 \mathrm{a}$ \\
\hline & Azoxystrobin + metalaxyl & $93 \mathrm{ab}$ & $20.0 \mathrm{a}$ \\
\hline & $\begin{array}{l}\text { Thiabendazole + ipconazole } \\
+ \text { azoxystrobin + metalaxyl }\end{array}$ & $93 \mathrm{ab}$ & $18.7 \mathrm{ab}$ \\
\hline \multirow[t]{6}{*}{ Symptomatic } & Untreated control & 73 de & $12.0 \mathrm{c}$ \\
\hline & Metalaxyl & $63 \mathrm{e}$ & $13.0 \mathrm{bc}$ \\
\hline & Thiabendazole + metalaxyl & $82 \mathrm{bcd}$ & $16.7 \mathrm{abc}$ \\
\hline & Ipconazole + metalaxyl & $88 \mathrm{abc}$ & $16.7 \mathrm{abc}$ \\
\hline & Azoxystrobin + metalaxyl & 75 de & $12.7 \mathrm{c}$ \\
\hline & $\begin{array}{l}\text { Thiabendazole }+ \text { ipconazole } \\
+ \text { azoxystrobin + metalaxyl }\end{array}$ & $78 \mathrm{~cd}$ & $20.0 \mathrm{a}$ \\
\hline
\end{tabular}

${ }^{2}$ Asymptomatic seeds appeared healthy and uniform in color and size, but had $16 \% \mathrm{~A}$. rabiei infection. Symptomatic seeds contained lesions and had $73 \% A$. rabiei infection.

${ }^{y}$ Metalaxyl was applied at $16 \mathrm{~g} / 100 \mathrm{~kg}$ seed, thiabendazole was applied at $72 \mathrm{~g} / 100 \mathrm{~kg}$ seed, ipconazole was applied at $3 \mathrm{~g} / 100 \mathrm{~kg}$ seed, and azoxystrobin was applied at $5 \mathrm{~g} / 100 \mathrm{~kg}$ seed $(1 \mathrm{~g} / 100 \mathrm{~kg}$ seed $=0.0160 \mathrm{oz} / 100 \mathrm{lb}$ seed).

xThe day the first lesion developed on aboveground plant parts was recorded and is presented here as the day after planting (DAP)

"Values followed by the same letter within a column are not significantly different $(\alpha=0.05)$ according to Fisher's protected least significant difference test.

infection (Chongo and Gossen, 2003 ). Because of the low emergence rate with the untreated seed at Fargo due to Pythium infection, it is important to make comparisons with the metalaxyl-alone treatment. In all trials except the Fargo field trial, fungicide seed treatments had no significant effect on emergence or ascochyta blight development on plants from asymptomatic seeds compared with untreated seed. In addition, fungicide seed treatments had no significant effect on emergence or ascochyta blight development on plants from asymptomatic seeds compared with metalaxyl-alone treated seeds in all trials. Previously reported evaluations of fungicide seed treatments on $A$. rabiei-infected seeds have been conducted on seed with high levels of natural infection or artificial infection (Demirci et al., 2003; Gaur, 2003; Kaiser and Hannan, 1988; Kaiser et al., 1973; Maden, 1983), and to our knowledge, this is the first reported evaluation of fungicide seed treatments on seed with a natural $A$. rabiei infection rate as low as $16 \%$.

In symptomatic seeds, seedling emergence and development of ascochyta blight on plants was affected by fungicide seed treatments, in some cases. Fungicides that were found to increase plant emergence compared with the untreated control or metalaxyl alone treatment were thiabendazole + metalaxyl, ipconazole + metalaxyl, and the mixture of all the fungicides (thiabendazole + ipconazole + azoxystrobin + metalaxyl). Multiple research studies have shown the effectiveness of thiabendazole at increasing germination or seedling emergence of $A$. rabiei-infected seed (Gaur, 2003; Kaiser and Hannan, 1988; Kaiser et al., 1973; Maden, 1983). In our studies, thiabendazole + metalaxyl significantly increased emergence over the metalaxyl-alone treatment in the growth chamber trial only, and did not increase emergence in the field trials compared with the metalaxyl-alone treatment.

Azoxystrobin has been reported to decrease the number of seedlings with ascochyta blight when used to treat $A$. rabiei-infected seed (Demirci et al., 2003). Azoxystrobin did not slow down the development of disease in our growth chamber trial, and the number of days after planting to disease appearance on seedlings from symptomatic seed treated with azoxystrobin was very similar to that of the untreated symptomatic seed. Recently, a baseline sensitivity level of $A$. rabiei to azoxystrobin was published (Wise et al., 2008), and a fungicide-resistance monitoring program was established in North Dakota (Wise et al., 2009). Isolates obtained from the $A$. rabiei-infected seed used in our study were tested for their sensitivity to azoxystrobin in vitro as part of the fungicide-resistance monitoring program, and were found to be significantly less sensitive to azoxystrobin than baseline $A$. rabiei isolates (Wise et al., 2008, 2009). This could partially explain why azoxystrobin was not effective in reducing the number of plants affected with ascochyta blight in our research trials, and may be an indicator that reduced sensitivity to azoxystrobin in vitro may also mean a reduced level of control in vivo with azoxystrobin. The only fungicide seed treatment that significantly slowed down the development of disease in seedlings was the metalaxyl + thiabendazole + ipconazole + azoxystrobin treatment. This treatment represents three different a.i. from different fungicide classes and different modes of action that have been reported to have efficacy on $A$. rabiei, the methyl benzimidazole carbamates [MBC (thiabendazole)], the demethylation inhibitors [DMI (ipconazole)], and the quinone outside inhibitors [QoI (azoxystrobin)] (Demirci et al., 2003). Of these three ingredients, only ipconazole is not currently registered for use on chickpea in the United States as a seed treatment (McMullen and Markell, 2008). The addition of an effective DMI fungicide, such as ipconazole, could potentially slow down the development and spread of $A$. rabiei resistance to QoI fungicides, such as azoxystrobin. Because of the seedborne nature of $A$. rabiei and the fact that $A$. rabiei isolates with reduced sensitivity to QoI fungicides have already been reported in the United States and Canada (Chang et al., 2007; Wise et al., 2009), it is important that effective fungicides with different modes of action are registered for use as a seed treatment on chickpea.

\section{Literature cited}

Akem, C., S. Kabbabeh, and S. Ahmed. 2004a. Integrating cultivar resistance with a single fungicide spray to manage ascochyta blight for increased chickpea yields. Plant Pathol. J. 3:105-110. 
Akem, C., S. Kabbabeh, and S. Ahmed. 2004b. Integrating cultivar resistance and seed treatment with planting dates to manage chickpea ascochyta blight. Plant Pathol. J. 3:111-117.

Chang, K.F., H.U. Ahmed, S.F. Hwang, B.D. Gossen, S.E. Strelkov, S.F. Blade, and G.D. Turnbull. 2007. Sensitivity of field populations of Ascochyta rabiei to chlorothalonil, mancozeb and pyraclostrobin fungicides and effect of strobilurin fungicides on the progress of ascochyta blight of chickpea. Can. J. Plant Sci. 87:937-944.

Chen, W., C.J. Coyne, T.L. Peever, and F.J. Muehlbauer. 2004. Characterization of chickpea differentials for pathogenicity assay of ascochyta blight and identification of chickpea accessions resistant to Didymella rabiei. Plant Pathol. 53:759-769.

Chen, W., K.E. McPhee, and F.J. Muehlbauer. 2005. Use of a mini-dome bioassay and grafting to study resistance of chickpea to ascochyta blight. J. Phytopathol. 153:579-587.

Chongo, G. and B.D. Gossen. 2003. Diseases of chickpea, p. 185-190. In: K.L. Bailey, B.D. Gossen, R.K. Gugel, and R.A.A. Morrall (eds.). Diseases of field crops in Canada. Canadian Phytopathological Soc., Saskatoon, Canada.

Chongo, G., B.D. Gossen, L. Buchwaldt, T. Adhikari, and S.R. Rimmer. 2004. Genetic diversity of Ascochyta rabiei in Canada. Plant Dis. 88:4-10.

Chongo, G., L. Buchwaldt, B.D. Gossen, G.P. Lafond, W.E. May, E.N. Johnson, and T. Hogg. 2003. Foliar fungicides to manage ascochyta blight (Ascochyta rabiei) of chickpea in Canada. Can. J. Plant Pathol. 25:135-142.

Demirci, F., H. Bayraktar, I. Babaliogullu, F.S. Dolar, and S. Maden. 2003. In vitro and in vivo effects of some fungicides against the chickpea blight pathogen, Ascocbyta rabiei. J. Phytopathol. 151:519-524.

Dey, S.K. and G. Singh. 1994. Seedborne infection of Ascochyta rabiei in chickpea and its transmission to aerial plant parts. Phytoparasitica 22:31-37.

Gan, Y.T., K.H.M. Siddique, W.J. MacLeod, and P. Jayakumar. 2006. Management options for minimizing the damage by ascochyta blight (Ascochyta rabiei) in chickpea (Cicer arietinum L.). Field Crops Res. 97:121-134.

Gaur, R.B. 2003. Eradication of seedborne inoculum of Ascochyta rabiei (Pass.) Lab. by fungicidal and thermal treatment of chickpea seeds. Indian J. Plant Protection 31:68-72.

Hewitt, H.G. 1998. Fungicides in crop protection. CAB International, New York.

Kaiser, W.J. 1997. Inter- and intranational spread of Ascochyta pathogens of chickpea, faba bean, and lentil. Can. J. Plant Pathol. 19:215-224.

Kaiser, W.J. and R.M. Hannan. 1988. Seed transmission of Ascochyta rabiei in chickpea and its control by seed-treatment fungicides. Seed Sci. Technol. 16:625637.

Kaiser, W.J., M. Okhovat, and G.H. Mossahebi. 1973. Effect of seed-treatment fungicides on control of Ascochyta rabiei in chickpea seed infected with the pathogen. Plant Dis. Rptr 57:742-746.

Maden, S. 1983. Transmission of seedborne infections of Ascochyta rabiei (Pass.) Labr. to seedlings and its control. J. Turkish Phytopathol. 12:77-82.

Maden, S., D. Singh, S.B. Mathur, and P. Neergaard. 1975. Detection and location of seed-borne inoculum of Ascochyta rabiei and its transmission in chickpea (Cicer arietinum). Seed Sci. Technol. 3:667-681.

Markell, S., K. Wise, K. McKay, R. Goswami, and N. Gudmestad. 2008. Ascochyta blight of chickpea. North Dakota State Ext. Rpt. No. PP-1362.

Mathur, S.B. and O. Kongsdal. 2003. Common laboratory seed health testing methods for detecting fungi. International Seed Testing Assn., Bassersdorf, Switzerland.

McMullen, M.P. and S.G. Markell. 2008. North Dakota field crop fungicide guide. North Dakota State University, Fargo.

Morrall, R.A.A. and D.L. McKenzie. 1974. A note on the inadvertent introduction to North America of Ascochyta rabiei, a destructive pathogen of chickpea. Plant Dis. Rptr. 58:342-345.

Nene, Y.L. and M.V. Reddy. 1987. Chickpea diseases and their control, p. 233-270. In: M.C. Saxena and K.B. Singh (eds.). The chickpea. CAB International, Oxon, UK.

Shtienberg, D., H. Vintal, S. Brener, and B. Retig. 2000. Rational management of Didymella rabiei in chickpea by integration of genotype resistance and postinfection application of fungicides. Phytopathology 90:834-842.

Wise, K.A., C.A. Bradley, J.S. Pasche, and N.C. Gudmestad. 2009. Resistance to QoI fungicides in Ascochyta rabiei from chickpea in the northern Great Plains. Plant Dis. 93:528-536.

Wise, K.A., C.A. Bradley, J.S. Pasche, N.C. Gudmestad, F.M. Dugan, and W. Chen. 2008. Baseline sensitivity of Ascochyta rabiei to azoxystrobin, pyraclostrobin, and boscalid. Plant Dis. 92:295-300. 